\title{
ANALISIS PROFITABILITAS DAN DISTRIBUSI PENDAPATAN USAHA PENANGKAPAN IKAN MENGGUNAKAN PUKAT CINCIN MINI DI KABUPATEN TUBAN, JAWA TIMUR
}

\author{
Tajerin, Manadiyanto, dan Sapto Adi Pranowo*)
}

\begin{abstract}
ABSTRAK
Keberhasilan usaha penangkapan ikan sebagai bagian sistem bisnis, tidak hanya dinilai dari profitabilitasnya juga keadilan dalam sistem distribusi pendapatan. Kajian terhadap kedua aspek tersebut pada usaha penangkapan ikan menggunakan pukat cincin mini telah dilakukan di Kabupaten Tuban dengan metoda survai. Hasil kajian menunjukkan bahwa usaha penangkapan ikan menggunakan pukat cincin mini di Kabupaten Tuban berada pada kondisi usaha yang menunjukkan gejala ke arah kurang menguntungkan dan mendekati tidak efisien. Distribusi pendapatan yang dihasilkan dari hasil usaha penangkapan ikan tersebut adalah sebagai berikut: $14,92 \%$ untuk nelayan pemilik, $18,20 \%$ untuk nelayan pandega dan $66,88 \%$ untuk penerimaan yang diperhitungkan tetapi tidak diterima baik oleh pemilik maupun pendega (current input).
\end{abstract}

\begin{abstract}
An analysis of profitability and income distribution of mini purse seine capture in Tuban district, East Java. By: Tajerin, Manadiyanto and Sapto Adi Pranowo

The success of capture fishery should be measured not only in terms of profitabilitas, but also based on income distribution system. A study on these two aspects in mini purse seine fishery has been carried out in district of Tuban, using survey methods. The result of this study indicated that the fishery is hardly profitable and inefficient. Mean while, income distribution was found follow this formula: $14.29 \%$ goes to owner, $18.20 \%$ goes to labour fishermen and $66.88 \%$ goes to other parties.
\end{abstract}

KEYWORDS: $\quad$ profitability, income distribution, mini purse seine, Tuban, East Java

\section{PENDAHULUAN}

Indonesia merupakan negara dengan perairan yang luas dan memiliki potensi perikanan laut yang besar. Bila potensi tersebut dikelola secara efisien, adil dan berkelanjutan dalam suatu kerangka sistem bisnis yang tangguh akan dapat memberikan kontribusi secara nyata bagi peningkatan kesejahteraan para pelakunya (terutama nelayan) dan peningkatan pertumbuhan ekonomi serta mampu memelihara kelestarian sumberdaya ikan beserta lingkungannya. Untuk itu diperlukan kebijakan dan program terobosan (breakthrough programs) secara tepat dan benar serta mampu mencapai tujuannya

Kebijakan dan program yang berkaitan dengan upaya optimalisasi antara ketersediaan sumberdaya (stock) ikan dengan tingkat penangkapan pada suatu wilayah penangkapan ikan (fishing ground) adalah sangat penting untuk menjamin sistem bisnis perikanan tangkap yang menguntungkan (profitable) secara berkelanjutan

Meskipun secara nasional potensi ikan masih belum dimanfaatkan secara penuh (underutilized) yaitu baru berkisar kurang lebih $64 \%$ dari potensi lestari (Nurhakim et al., 1998), namun keadaan ini ternyata tidak berlaku untuk seluruh perairan Indonesia (Winarso et al., 2001). Apabila tingkat penangkapan ikan di suatu wilayah penangkapan melebihi potensi lestari (maximum sustainable yields/MSY), maka akan terjadi fenomena tangkap lebih secara biologi (biological overfishing) yang akan berakibat pada menurunnya hasil tangkapan per satuan upaya (catch per unit of effort/CPUE). Di sisi lain penurunan hasil tangkapan akan menurunkan penerimaan dan pendapatan nelayan sehingga menjadikan usaha penangkapan ikan berjalan dengan tingkat profitabilitas rendah dan bagian pendapatan yang diterima nelayan juga menjadi rendah.

Perairan laut merupakan sumberdaya alam milik bersama (common property), dimana para nelayan mempunyai hak yang sama untuk memanfaatkan sumberdaya atau melakukan usaha penangkapan. Penggunaan jenis alat tangkap yang sesuai menduduki peranan sangat penting dalam pemanfaatan sumberdaya perairan laut baik pelagis, demersal maupun oseanis

\footnotetext{
*) Peneliti pada Pusat Riset Pengolahan Produk dan Sosial Ekonomi Kelautan dan Perikanan
} 
Pada umumnya nelayan di pantai utara Jawa, seperti halnya dengan nelayan di Kabupaten Tuban melakukan penangkapan ikan pelagis. Jenis alat tangkap yang biasa digunakan nelayan untuk menangkap ikan pelagis adalah pukat cincin mini. Prinsip penangkapan menggunakan pukat cincin mini sesuai dengan sifat ikan pelagis yang suka bergerombol (schooling), yaitu menghadang pergerakan ikan ke arah horizontal dengan cara melingkari kelompok ikan pelagis dan menghadang pergerakan ikan ke arah vertikal (Waluyo, 1993; Barus dan Nasution, 1982).

Keberhasilan usaha penangkapan menggunakan pukat cincin mini dilihat dari aspek finansial akan sangat dipengaruhi oleh beberapa faktor seperti permodalan, biaya operasional, tenaga kerja, hasil tangkapan dan harga produk. Perbedaan faktor-faktor tersebut akan menyebabkan perbedaan pada distribusi pendapatan nelayan, baik nelayan pemilik ataupun nelayan pandega. Oleh karena itu, perlu dilakukan riset untuk mengetahui profitabilitas dan distribusi pendapatan pada usaha penangkapan ikan menggunakan pukat cincin mini. Hasil riset in diharapkan dapat berguna bagi penentu kebijakan sebagai bahan pertimbangan dalam merumuskan program dan kebijakan pembangunan perikanan laut, khususnya di Kabupaten Tuban, Jawa Timur.

\section{METODE}

\section{Penentuan Lokasi dan Penetapan Sampel}

Riset ini dilakukan di Kabupaten Tuban, Jawa Timur pada Nopember 2002. Kabupaten Tuban dipilih sebagai lokasi riset dengan pertimbangan daerah ini merupakan salah satu daerah yang memiliki basis perikanan laut yang menonjol dengan jumlah penggunaan alat tangkap pukat cincin mini yang tergolong besar di Jawa Timur (Ditjen Perikanan Tangkap, 2001)

Kajian ini dalam pelaksanaannya dilakukan dengan pendekatan metoda survai dengan mengambil sampel responden secara acak (random sampling). Jumlah responden yang diambil sebanyak 15 orang nelayan pemilik atau lebih dari $10 \%$ populasi nelayan pemilik. Usaha penangkapan ikan menggunakan pukat cincin mini di Kabupaten Tuban, Jawa Timur yang berjumlah 100 orang

\section{Jenis dan Cara Pengumpulan Data}

Jenis data yang dikumpulkan terdiri dari data primer dan sekunder. Data primer diperoleh secara langsung dari nelayan pemilik sebagai responden melalui wawancara menggunakan daftar pertanyaan terstruktur dengan pola terbuka dan tertutup.
Pertanyaan dengan pola terbuka seperti pertanyaanpertanyaan yang berkaitan dengan analisis profitabilitas usaha (biaya-biaya yang dikeluarkan, hasil tangkapan, harga ikan dan sebagainya), sedangkan pertanyaan dengan pola tertutup seperti pertanyaan yang menyangkut status responden dalam kegiatan usaha yang dihubungkan dengan distribusi pendapatan nelayan.

Adapun data primer yang diperlukan antara lain: permodalan, biaya produksi, harga jual produksi, tenaga kerja, sistem pembagian hasil antara nelayan pemilik dengan nelayan pandega. Sedangkan data sekunder diperoleh dari instansi terkait seperti Dinas Perikanan dan Kelautan Kabupaten Tuban dan sumber publikasi lainnya. Data sekunder yang diperlukan antara lain data tentang keadaan umum perikanan daerah riset

\section{Metoda Analisis Data}

Data yang diperoleh dalam riset ini dianalisis secara deskriptif, khususnya pada analisis yang berhubungan dengan profitabilitas usaha dan distribusi pendapatan Secara umum, analisis profitabilitas bertujuan untuk mengukur seberapa besar kemampuan suatu usaha memperoleh keuntungan dalam hubungannya dengan penjualan, penerimaan maupun keuntungan modal sendiri sehingga dapat diketahui layak tidaknya suatu investasi dalam usaha tersebut (Arifin, 2000). Analisis profitabilitas dilakukan dengan pendekatan finansial yang meliputi: (1) analisis rasio penerimaan-biaya (RC Ratio), (2) analisis rentabilitas, (3) analisis periode kembali modal. Sedangkan analisis distribusi pendapatan dengan pendekatan akuntansi.

Analisis rasio penerimaan-biaya dimaksudkan untuk mengetahui besarnya nilai perbandingan penerimaan dan biaya produksi yang digunakan. Rumus perhitungan analisis ini seperti dikemukakan Hernanto (1998) dan Sisdjatmiko (1990) adalah sebagai berikut:

Rasio Penerimaan-Biaya $=\frac{\text { Total Penerimaan }}{\text { Total Biaya }}$

Kriteria yang digunakan adalah

RC Ratio $>1$, berarti usaha menghasilkan keuntungan

RC Ratio $=1$, berarti usaha tidak untung dan tidak rugi (impas)

$\mathrm{RC}$ Ratio $<1$, berarti usaha mengalami kerugian

Analisis rentabilitas adalah suatu analisis yang menunjukkan perbandingan antara laba dengan aktiva 
atau modal yang menghasilkan laba tersebut. Dengan kata lain rentabilitas adalah kemampuan suatu usaha untuk menghasilkan laba selama periode tertentu. Nilai rentabilitas di atas 25\% menunjukkan bahwa usaha tersebut bekerja pada kondisi efisien dan sebaliknya bila sama dengan atau di bawah $25 \%$ (Riyanto, 1995). Dalam kajian ini pengukuran rentabilitas dilakukan dengan pendekatan "rasio aktiva-laba ekonomi", dengan rumus sebagai berikut:

Rentabilitas $=\underline{\text { Laba Usaha setelah Pajak }} \times 100 \%$ Ekonomi Total Aktiva

Dimana laba usaha setelah pajak dalam hal ini adalah jumlah keuntungan bersih yaitu penerimaan total dikurangi dengan biaya total termasuk biaya pajak, sedangkan total aktiva adalah total biaya variabel per trip ditambah dengan total investasi awal.

Analisis periode kembali modal digunakan untuk mengetahui lamanya perputaran modal investasi yang digunakan dalam melakukan usaha atau dengan kata lain untuk mengetahui waktu yang dapat digunakan untuk menutup kembali pengeluaran investasi dengan menggunakan keuntungan sebagai perbandingan (Riyanto, 1995). Besarnya nilai periode kembali modal dapat dihitung dengan menggunakan rumus:

Periode Kembali $=\underline{\text { Modal Investasi Awal }} \times 1$ tahun Modal Keuntungan

Periode kembali modal tersebut selanjutnya dibandingkan dengan periode kembali modal maksimum. Besarnya nilai periode kembali modal masksimum adalah waktu yang dibutuhkan untuk mendapatkan keuntungan sebesar nilai investasi yang ditanam dengan jalan mendepositokan uang sebesar investasi tersebut.

Kriteria yang digunakan adalah:

Apabila Periode Kembali Modal Usul dan < Periode kembali Modal Maksimum; berarti investasi lebih menguntungkan bila digunakan untuk usaha penangkapan ikan menggunakan pukat cincin mini.

Apabila Periode Kembali Modal Usulan > Periode Kembali Modal Maksimum; berarti investasi usaha penangkapan ikan menggunakan pukat cincin mini tidak efisien.

Analisis distribusi pendapatan bertujuan untuk mengetahui berapa persen dari pendapatan hasil tangkapan yang diterima oleh masing-masing kelompok yang terlibat langsung dalam proses penangkapan ikan, yaitu kelompok nelayan pemilik, nelayan pandega serta bagian hasil yang ditransfer keluar sektor perikanan (current input). Untuk mengetahui distribusi pendapatan masing-masing kelompok tersebut digunakan perhitungan faktor share dengan pendekatan akuntansi (Purwanti, 1994). Adapun rumus yang digunakan dalam perhitungan faktor share tersebut adalah sebagai berikut:

Faktor $/=$ Bagian Pendapatan yang Diterima $\times 100 \%$ Share Nilai Total Hasil Tangkapan

\section{HASIL DAN BAHASAN}

\section{Karakteristik dan Struktur Masyarakat Nelayan}

\section{Karakteristik nelayan}

Karakteristik nelayan responden dilihat dari aspek pendidikan didominasi oleh tingkat pendidikan tamat SD yaitu sebanyak $53,33 \%$. Persentase tersebut mengindikasikan bahwa kesadaran pentingnya pendidikan pada masyarakat nelayan mulai tumbuh, setidaknya terlihat dari persentase nelayan yang mampu mengikuti pendidikan SD dan SLTP sebanyak $80 \%$ (Tabel 1).

Dari segi umur, responden didominasi oleh kelompok nelayan berumur 40-59 tahun yaitu sebanyak $46,67 \%$, sedangkan sisanya sebanyak $33,33 \%$ berumur antara 20-39 tahun dan sebanyak 20,00\%

Tabel 1. Sebaran tingkat pendidikan responden

Table 1. Distribution of respondent education level

Tingkat Pendidikan/ Level of Education

Frekwensi (orang)/ Persentase/

Frequency (person) Percentage\%

\begin{tabular}{lll}
\hline Tidak tamat SD/Elementary School Uncompletted & 3 & 20,00 \\
Tamat SD/Elementary School Completted & 8 & 53,33 \\
Tamat SLTP/Intermediate School Completted & 4 & 26,67 \\
\hline
\end{tabular}


Tajerin, Manadiyanto dan S. A. Pranowo

Tabel 2. Sebaran tingkat umur responden

Table 2. Distribution of respondent age level

$\begin{array}{ccc}\text { Tingkat Umur (Tahun)l } & \text { Frekwensi (orang)/ } & \text { Persentase/ } \\ \text { Level of Age (Year) } & \text { Frequency (person) } & \text { Percentage } \%\end{array}$

\begin{tabular}{ccc}
\hline$<20$ & 3 & 20,00 \\
$20-39$ & 5 & 33,33 \\
$40-59$ & 7 & 46,67 \\
\hline
\end{tabular}

Tabel 3. Sebaran jumlah anggota keluarga responden

Table 3. Distribution of respondent family amount

\begin{tabular}{ccc}
\hline $\begin{array}{c}\text { Jumlah anggota keluarga (Orang)/ } \\
\text { Amount of family (Mans) }\end{array}$ & $\begin{array}{c}\text { Frekwensi (orang)/ } \\
\text { Frequency (person) }\end{array}$ & $\begin{array}{c}\text { Persentase/ } \\
\text { Percentage\% }\end{array}$ \\
\hline$<3$ & 5 & 33,33 \\
$4-5$ & 8 & 53,33 \\
$6-9$ & 2 & 13,33 \\
\hline
\end{tabular}

berumur di bawah 20 tahun (Tabel 2). Hal ini menunjukkan bahwa sebagaian besar responden adalah tergolong pada kelompok usia produktif (2039 tahun)

Komposisi kelompok umur responden berimplikasi kepada tinggi rendahnya angka beban tanggungan keluarga. Berdasarkan besarnya jumlah anggota keluarga dapat diketahui bahwa 33,33\% responden memiliki keluarga kurang dari tiga orang, 53,33\% memiliki keluarga antara empat sampai lima orang dan selebihnya $(13,33 \%)$ memiliki keluarga di atas lima orang (Tabel 3).

Salah satu faktor utama yang dijadikan pertimbangan responden untuk menekuni pekerjaannya sebagai nelayan adalah adanya faktor keterampilan yang didapat secara turun-temurun melalui transfer dalam bentuk keterampilan atau pengetahuan dari orang tua atau nelayan pendahulunya (transfer knowledge).

\section{Struktur masyarakat nelayan}

Struktur masyarakat nelayan dapat dibedakan menjadi dua kelompok, yaitu nelayan pemilik alat tangkap dan nelayan buruh. Masing-masing kelompok tersebut memiliki peran khusus di dalam proses produksi sampai pemasaran hasil (Gambar 1).

Nelayan pemilik lebih dikenal dengan nelayan juragan darat. Berdasarkan tujuan usaha, besarnya modal maupun perannya dalam usaha, maka pemilik dapat dibedakan menjadi dua sub kelompok yaitu nelayan pemilik tradisional dan nelayan pemilik non tradisional. Nelayan pemilik tradisional menggunakan modal investasi yang lebih kecil dengan tujuan usaha sekedar untuk mempertahankan hidup (subsisten), belum mempunyai motif mencari keuntungan secara nyata. Umumnya nelayan pemilik tradisional ini berperan sebagai nakhoda (juragan laut), sedangkan nelayan pemilik non tradisional ditandai dengan penggunaan modal investasi yang lebih besar, tujuan usaha mengarah pada keuntungan nyata dan pembagian peran antara nelayan pemilik dan pandega jelas (Harahap, 1993).

Nelayan pemilik pada alat tangkap pukat cincin mini di Tuban termasuk dalam kelompok nelayan pemilik non tradisional, karena usaha penangkapan dengan alat tangkap ini mempergunakan modal yang cukup besar, mempunyai motif usaha untuk mencari keuntungan secara nyata, dan terdapat perbedaan yang jelas dalam pembagian kerja yang tercermin dalam sistem bagi hasil yang berlaku pada usaha tersebut di mana antara nelayan pemilik dengan nelayan pandega maupun antar nelayan pandega mempunyai bagian hasil yang berbeda sesuai dengan peran dan kedudukannya dalam penangkapan.

Hubungan antara nelayan pemilik maupun nelayan buruh pada dasarnya bersifat saling membutuhkan. Meskipun demikian, karena posisinya yang lemah, buruh (pandega) cenderung lebih bergantung pada nelayan pemilik (juragan darat), terutama pada saat musim paceklik. Pada saat tidak ada hasil tangkapan (paceklik) nelayan buruh (pandega) meminjam uang 


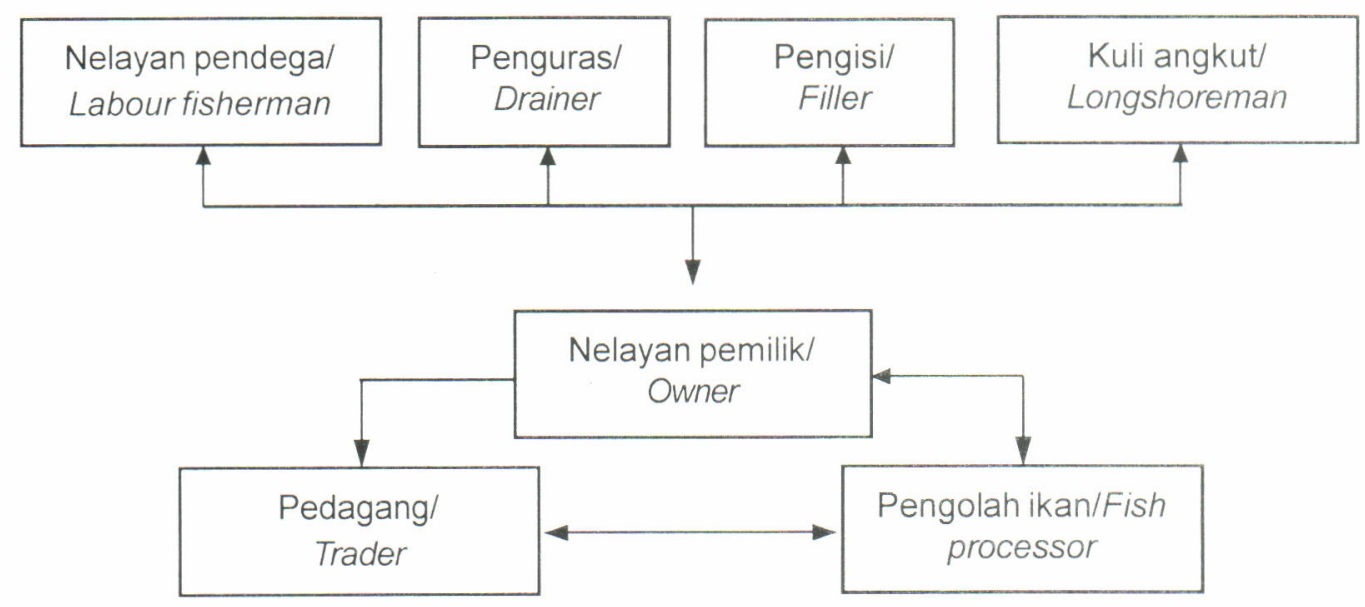

Gambar 1. Hubungan antara nelayan pemilik, nelayan pandega, penguras, pengisi,kuli angkut, pedagang dan pengolah ikan di Kabupaten Tuban

Figure 1. Relationship between owner fisherman, labour fisherman, drainer, filler, longshoreman, trader and fish processor in Tuban District

kepada nelayan pemilik untuk memenuhi kebutuhan hidup keluarganya. Dengan adanya pinjaman tersebut maka nelayan pemilik (juragan darat) telah mengikat buruh (pandega) agar tidak berpindah ke nelayan pemilik lainnya

Jumlah nelayan buruh dalam satu unit penangkapan dengan alat tangkap pukat cincin mini berkisar 15-20 orang per unit. Jumlah nelayan di Tuban jika dibandingkan dengan jumlah penduduk keseluruhan hanya 16,51\%. Namun sebagai akibat tingginya produksi ikan yang dihasilkan, mereka mampu melibatkan jumlah penduduk yang lebih besar dalam usaha perikanan yaitu pedagang, penguras, pengisi, kuli angkut maupun pengolah ikan.

Sebagian besar $(90 \%)$ responden pedagang memberikan pinjaman kepada nelayan pemilik sebagai suatu ikatan sehingga nelayan pemilik mempunyai kewajiban untuk menjual hasil tangkapannya kepada pedagang tersebut. Nelayan pemilik dan pedagang juga mempunyai hubungan dengan pengolah ikan sebagai konsumen, pengolah ikan pun membutuhkan pedagang dan nelayan pemilik untuk mensuplai bahan baku.

Untuk transportasi hasil tangkapan mulai dari perahu sampai ke TPI, nelayan membutuhkan tenaga kuli angkut sehingga diantara keduanya mempunyai hubungan yang saling menguntungkan karena kuli angkut juga membutuhkan nelayan pemilik untuk mendapatkan penghasilan.

\section{Analisis Profitabilitas}

Kegiatan usaha penangkapan ikan di laut di samping merupakan salah satu kegiatan mata pencaharian bagi sebagian masyarakat, kegiatan ini juga sekaligus merupakan kegiatan investasi yang tidak sedikit. Satu unit lengkap armada penangkapan ikan pada intinya terdiri atas empat komponen utama, yaitu: kapal, alat tangkap, motor dan peralatan bantu lainnya. Adapun spesifikasi teknis, kapal dan mesin yang digunakan pada armada penangkapan pukat cincin mini tersebut tertera pada Tabel 4.

Rata-rata nilai investasi awal usaha penangkapan ikan menggunakan pukat cincin mini adalah sebesar Rp. 264.600.000,-, sedangkan nilai sekarang investasi justru meningkat menjadi sebesar Rp.340.600.000,$\mathrm{Hal}$ ini terjadi karena adanya depresiasi nilai tukar rupiah terhadap dollar Amerika, sehingga nilai sekarang menyesuaikan terhadap besarnya depresiasi tersebut.

Investasi dalam usaha penangkapan ikan di laut, pada dasarnya dihadapkan kepada resiko yang harus dibayar yaitu berupa penyusutan dari barang investasi yang digunakan. Dengan menggunakan metoda garis lurus (straight line balance method) dimana beban penyusutan diseragamkan per tahunnya, diketahui bahwa penyusutan tahunan untuk kapal adalah sebesar Rp. 15.000.000,-, alat tangkap sebesar Rp 11.250.000,--, mesin sebesar Rp. 3.125.000,- dan alat bantu lainnya sebesar Rp. 625.000,-. Total nilai penyusutan keempat barang investasi tersebut adalah sebesar Rp. 30.000.000,-. Nilai penyusutan ini termasuk dalam biaya tetap yang diperhitungkan dengan tidak terpengaruh oleh volume maupun nilai produksi

Selain dari besarnya nilai penyusutan, biaya tetap juga termasuk di dalamnya besarnya biaya oportunitas 
Tajerin, Manadiyanto dan S. A. Pranowo

Tabel 4. Spesifikasi teknis armada penangkapan ikan dengan pukat cincin mini

Table 4. Technical spesification of mini purse seine fishing gear

\begin{tabular}{|c|c|}
\hline Komponen/Component & Spesifikasi te knis/Technical specifications \\
\hline Kapal/Boat & $\begin{array}{l}\text { - Bahan: Kayu/Materials: Woods } \\
\text { - Tonase/ Tonage 13-29 GT } \\
\text { - Ukuran PxLxD/Size } L \times W \times D: \\
\text { 14.30m } \times 4.80 \mathrm{~m} \times 1.45 \mathrm{~m} \text { sampai dengan/up to } \\
\text { 16.00m } \times 5.10 \mathrm{~m} \times 1.75 \mathrm{~m}\end{array}$ \\
\hline Mesin/Machine & $\begin{array}{l}\text { - Jenis/kinds: Colt Diesel, Mitsubishi } \\
\text { - Kekuatan/Power: 50-95 PK/HP } \\
\text { - Tahun/ Year: } 1990-1996\end{array}$ \\
\hline
\end{tabular}

investasi yang dihitung berdasarkan beban bunga pinjaman pada bank yang berlaku pada saat awal melakukan peminjaman atau mengadakan barang investasi tersebut, secara keseluruhan total biaya oportunitas tersebut sebesar Rp. 5.995.000,-. Dengan demikian diketahui bahwa total biaya tetap per tahun untuk usaha penangkapan ikan menggunakan pukat cincin mini adalah sebesar Rp. 62.470.000,--. Secara rinci uraian mengenai biaya tetap tersebut pada Tabel 5.

Di samping biaya tetap, usaha penangkapan tersebut juga mengeluarkan biaya tidak tetap yang

Tabel5. Rataan besarnya biaya tetap usaha penangkapan ikan menggunakan pukat cincin mini di Kabupaten Tuban, Jawa Timur, 2002

Tabel 5. Average of fixed cost for fish capture in mini purse seine in Tuban District, East Java, 2002

\begin{tabular}{|c|c|c|c|c|c|}
\hline \multirow[b]{2}{*}{ Uraian/descriptions } & \multicolumn{4}{|c|}{ Jenis Barang Investasi/ Kind of Investment Goods } & \multirow[b]{2}{*}{$\begin{array}{l}\text { Total / } \\
\text { Totals }\end{array}$} \\
\hline & $\begin{array}{l}\text { Kapal } \\
\text { Boat }\end{array}$ & $\begin{array}{l}\text { Alat tangkap } \\
\text { Fishing Gear }\end{array}$ & $\begin{array}{c}\text { Mesin } \\
\text { Machine }\end{array}$ & $\begin{array}{l}\text { Alat Bantu } \\
\text { Supplement } \\
\text { Tools }\end{array}$ & \\
\hline \multicolumn{6}{|l|}{ 1. Penyusutan/Depretiation: } \\
\hline $\begin{array}{l}\text { - Nilai Investasi Awal/ } \\
\text { Initial Investment Values } \\
\text { (Rp.) }\end{array}$ & 175.000 .000 & 60.500 .000 & 23.000 .000 & 6.100 .000 & 264.600 .000 \\
\hline $\begin{array}{l}\text { - Nilai Sekarang/ } \\
\text { Anuitas Values (Rp.) }\end{array}$ & 225.000 .000 & 90.000 .000 & 25.000 .000 & 625.000 & 340.600 .000 \\
\hline $\begin{array}{l}\text { - Umur Ekonomis/ } \\
\text { Economics Time (tahun / year) }\end{array}$ & 15 & 8 & 8 & 1 & \\
\hline $\begin{array}{l}\text { - Nilai Penyusutan/ } \\
\text { Depretiation Values (Rp.) }\end{array}$ & 15.000 .000 & 11.250 .000 & 3.125 .000 & 625.000 & 30.000 .000 \\
\hline \multicolumn{6}{|l|}{ 2. Opportunitas/Oppurtunity: } \\
\hline $\begin{array}{l}\text { - Bunga Pinjaman Bank } \\
\text { Bank Interest Rates (\%) }\end{array}$ & 20 & 20 & 20 & 20 & 20 \\
\hline $\begin{array}{l}\text { - Biaya Opportunitas Invetasi/ } \\
\text { Opportunities Cost (Rp.) }\end{array}$ & 3.000 .000 & 2.250 .000 & 625.000 & 120.000 & 5.995 .000 \\
\hline 3. Pemeliharaan/Maintenance & 6.500 .000 & 10.000 .000 & 10.000 .000 & 0 & 26.500 .000 \\
\hline $\begin{array}{l}\text { 4. Biaya Tetap Per Tahun/ } \\
\text { Fixed Cost Per Year (Rp.) }\end{array}$ & 24.500 .000 & 23.500 .000 & 13.750 .000 & 720.000 & 62.470 .000 \\
\hline
\end{tabular}


merupakan penjumlahan dari biaya tidak tetap sebelum beroperasi dan biaya tidak tetap setelah operasi serta nilai pendapatan bagian pandega

Berdasarkan hasil perhitungan, diperoleh besaran nilai rata-rata setahun untuk biaya tidak tetap sebelum beroperasi sebesar Rp. 129.025.000,--, biaya tidak tetap setelah beroperasi sebesar Rp. 31.730.042,- dan bagian pendapatan untuk pandega sebesar Rp. 52.501.104,-, sehingga total biaya tidak tetap (total variable cost) rata-rata setahun sebesar $\mathrm{Rp}$ 184.255.042,-. (Tabel 6).

Operasi penangkapan ikan di laut sangat dipengaruhi oleh kondisi musim, yaitu musim puncak, musim sedang dan musim paceklik ikan. Perbedaan musim ini berpengaruh terhadap fluktuasi produksi dan kestabilan harga ikan. Perbedaan musim akan mempengaruhi fluktuasi penerimaan dari satu musim ke musim lainnya. Pada gilirannya, keragaan suatu

Tabel 6. Rataan biaya tidak tetap usaha penangkapan ikan menggunakan pukat cincin mini di Kabupaten Tuban, Jawa Timur, 2002

Table 6. Average of fixed cost for fish capture with mini purse seine in Tuban District, East Java, 2002

Uraian/ltem

Jumlah/Totals

Operasi Per Trip/

1. Biaya Tidak Tetap Sebelum Operasi Per
Variable Cost before Operation Per Trip

a. Solar/Oil

b. Minyak Tanah/Cerosine

c. Pelumas/Lubricants

d. Garam/ Salt

e. Es/lce

f. Air Bersih/Clean water

g. Ransum Anak Buah Kapal/ Crew Meals

h. Lain-lain/ Others

Total Biaya Tidak Tetap Sebelum Operasi Per Trip/

Total of Variable Cost Before Operation Per Trip

Total Biaya Tidak Tetap Sesudah Operasi Per Tahun/

Total of Variable Cost After Operation Per Year

2. Biaya Tidak Tetap Setelah Operasi Per Tahun/

Variable Cost After Operation Per Year

i. Izin Usaha/Licency

j. Retribusi/Retribution

k. Biaya Lelang/Auction Cost

(Biaya Pengisi, Penguras dan Kuli Angkut/Cost of Fillers,

Drainers and Longshoremens )

I. Biaya Lain/Other Cost

- Biaya Lawuan/Cost of "Lamuan"

- Uang makan/Cost of Meal

Total Biaya lain/Total of other cost

Total Biaya Tidak Tetap Setelah Operasi Per Tahun/

Total of Variables Cost After Operation Per Year

3. Biaya pemeliharaan/Maintenance Cost

- Pemeliharaan Kapal/Maintenance of Boat

- Pemeliharaan Mesin/Maintenance of Machine

- Pemeliharaan Alat Tangkap/Maintenance of Fish net

Total Biaya Pemeliharaan/Total of Maintenance Cost

4. Total Biaya Tidak Tetap Per Tahun/Totals of Variable Cost Per Year
(Rp.)
1.440 .000
135.000
172.000
200.000
960.000
68.000
1.138 .000
849.500
4.962 .500

129.025 .000

150.000

10.732 .042

9.348 .000

3.630 .080

7.869 .920

11.500 .000

31.730 .042 
Tabel 7. Rataan penerimaan nelayan pada usaha penangkapan ikan menggunakan pukat cincin mini di Kabupaten Tuban, Jawa Timur, 2002

Table 7. Average of fishermen income from fish capture using mini purse seine in Tuban District, East Java, 2002

\begin{tabular}{|c|c|c|c|}
\hline Uraian/Item & $\begin{array}{c}\text { Musim } \\
\text { puncak/Peak } \\
\text { season }\end{array}$ & $\begin{array}{c}\text { Musim } \\
\text { sedang/Midlle } \\
\text { season }\end{array}$ & $\begin{array}{c}\text { Musim } \\
\text { paceklik/Slack } \\
\text { season }\end{array}$ \\
\hline $\begin{array}{l}\text { Hasil Tangkapan Rata-Rata Per Trip (kg) } \\
\text { Average Yield Per Trip (kg) }\end{array}$ & 7,525 & 3,675 & 542,5 \\
\hline 1. Layang/L ayang Scad (kg.) & 3.500 & 1.750 & 350 \\
\hline 2. Kembung/Striped Mackerel (kg.) & 2.100 & 1.050 & 52,5 \\
\hline 3. Tembang/Fingescale Sardine (kg.) & 1.050 & 525 & 35 \\
\hline 4. Lemuru//ndonesian Oil Sardine (kg.) & 525 & 262,5 & 87,5 \\
\hline 5. Tongkol/Frigate mackerel (kg.) & 350 & 87,5 & 17,5 \\
\hline $\begin{array}{l}\text { Harga Ikan Rata-Rata Per Trip (Rp)/ } \\
\text { Average Fish Price Per Trip (Rp) }\end{array}$ & 2.400 & 2.800 & 3.400 \\
\hline 1. Layang/Layang Scad (Rp) & 3.000 & 3.500 & 4.500 \\
\hline 2. Kembung/Striped Mackerel (Rp) & 2.500 & 3.000 & 3.500 \\
\hline 3. Tembang/Fingescale Sardine (Rp) & 2.000 & 2.500 & 3.000 \\
\hline 4. Lemuru/Indonesian Oil Sardine (Rp) & 1.000 & 1.250 & 2.000 \\
\hline 5. Tongkol/Frigate Mackerel (Rp) & 3.500 & 3.750 & 4.000 \\
\hline $\begin{array}{l}\text { Nilai Tangkapan Rata-Rata Per Trip (Rp) } \\
\text { Value of Average Catching Per Trip (Rp) }\end{array}$ & 16.800 .000 & 110.206 .250 & 6.321 .000 \\
\hline 1. Layang/Layang Scad (Rp) & 10.500 .000 & 5.775 .000 & 1.575 .000 \\
\hline 2. Kembung/Striped Mackerel (Rp) & 5.250 .000 & 2.835 .000 & 183.750 \\
\hline 3. Tembang/Fingescale Sardine (Rp) & 2.100 .000 & 770.000 & 105.000 \\
\hline 4. Lemuru/Indonesian Oil Sardine (Rp) & 525.000 & 315.000 & 175.000 \\
\hline 5. Tongkol/Frigate Mackerel (Rp) & 1.225 .000 & 323.750 & 70.000 \\
\hline $\begin{array}{l}\text { Jumlah Trip Per Musim (Frek.)/ } \\
\text { Sum of Trip Per Season (Freq.) }\end{array}$ & 12 & 11 & 3 \\
\hline $\begin{array}{l}\text { Penerimaan Per Tahun (Rp)/ } \\
\text { Revenue Per Year (Rp.) } \\
\text { (Nilai Tangkapan Rata-Rata Per Tahun)/ } \\
\text { (Value of Average Catching Per Year) }\end{array}$ & 235.200 .000 & 110.206 .250 & 6.321 .000 \\
\hline
\end{tabular}

usaha penangkapan ikan dengan tingkat produksi dan harga yang berfluktuasi menurut musim akan mempengaruhi kinerja profitabilitasnya. Secara rinci besarnya hasil tangkapan, harga dan penerimaan hasil pada masing-masing musim tersebut maupun ratarata setahun disajikan pada Tabel 7

Dari Tabel 7, diketahui bahwa total penerimaan per tahun yang diperoleh dari nilai tangkapan rata-rata per tahun adalah sebesar Rp. 351.727.250,--. Penerimaan ini merupakan penjumlahan dari penerimaan tiga musim, yaitu musim puncak sebesar Rp. 235.200.000,-, musim sedang sebesar Rp. 110.206.250,- dan musim paceklik sebesar Rp. 6.321.000,-

Uraian selanjutnya dilakukan pengukuran kinerja profitabilitas berdasarkan pada analisis rasio 
pengeluaran-biaya, rentabilitas dan periode kembali modal. Pada Tabel 8 terlihat secara rinci hasil perhitungan ketiga analisis rasio tersebut.

\section{Analisis Rasio Penerimaan Biaya}

Pukat cincin mini merupakan jenis alat tangkap ikan pelagis kecil yang cukup tinggi biaya investasinya, yaitu rata-rata sebesar $R p$. 264.600.000,-, dengan hasil tangkapan yang cukup besar yaitu rata-rata per trip sebanyak $7.525 \mathrm{~kg}$ pada musim puncak, sebanyak $3.675 \mathrm{~kg}$ pada musim sedang dan sebanyak $542,5 \mathrm{~kg}$ pada musim paceklik. Umumnya kapal dengan alat tangkap pukat cincin mini merupakan armada dengan jumlah anak buah kapal yang cukup banyak yaitu rata-rata 15-20 orang per unit kapal.
Dari Tabel 8, diketahui bahwa dengan hasii tangkapan total per tahun sebanyak $11.742 .5 \mathrm{~kg}$ per tahun dengan nilai penerimaan total sebesar Rp 351.727.250,- per tahun atau sebesar Rp. 13.527.971.05,- per trip. Sementara hasil analisis pada Tabel 5 dan Tabel 6 menunjukkan bahwa besarnya biaya penyusutasn asset yang merupakan total biaya tetap (TFC) adalah sebesar Rp 62.470 .000 ,- , total biaya variabel (TVC) sebesar Rp. 184.255.042,- total bagian pandega per tahun sebesar Rp. 52.501.104,--. Dengan demikian nilai Biaya Total (TC) adalah sebesar Rp. 299.226.146,-

Keuntungan usaha akan diperoleh apabila total penerimaan (total revenue) lebih besar dari total biaya (total cost) yang telah dikeluarkan. Untuk memperoleh tingkat keuntungan yang dihasilkan

Tabel 8. Analisis rasio pada usaha penangkapan ikan menggunakan pukat cincin mini selama satu tahun di Kabupaten Tuban, Jawa Timur, 2002

Tabel 8. Analysis of ratio for fish capture with mini purse seine during one year in Tuban District, East Java, 2002

\begin{tabular}{|c|c|}
\hline Uraian/ltem & $\begin{array}{l}\text { Nilai/Value } \\
\text { (Rp.) }\end{array}$ \\
\hline I. Penerimaan Total/Total Revenue (TR) & 351.727 .250 \\
\hline II. Biaya Total/Total Cost (TC) & 299.226 .146 \\
\hline 1. Total Biaya Tetap/Total Fixed Cost (TFC) & 62.470 .000 \\
\hline 2. Total Biaya Tidak Tetap/Total of Variable Cost (TVC) & 184.255 .042 \\
\hline $\begin{array}{l}\text { 3. Bagian Pandega/Labour Income Sharing (LIS) } \\
{[\text { LIS }=(\mathrm{NSV}-\mathrm{TFC}+\mathrm{TVC}) / 2]}\end{array}$ & 52.501 .104 \\
\hline III. Nilai Penjualan Bersih/ Netto Sales value (NSV= TR - TFC) & 289.257 .250 \\
\hline IV. Keuntungan/Profit $(\Pi=\mathrm{TR}-\mathrm{TC})$ & 52.501 .104 \\
\hline V. Analisis Rasio/Ratio Analysis: & \\
\hline 1. Rasio Penerimaan Biaya/Revenue Cost Ratio (TR/TC) & 1,18 \\
\hline 2. Rentabilitas/Rentability $((R=\Pi /(T V C t+I C I) \times 100 \%)$ & $19.32 \%$ \\
\hline 3. Periode Kembali Modal/Payback Period (PP $=\mid \mathrm{Cl} / \Pi \times 1$ Tahun) & 5.04 tahun/year \\
\hline $\begin{array}{l}\text { 4. Periode kembali Modal Maksimum/Payback Period Maximum } \\
\text { (PPmax }=\mathrm{ICl} / \mathrm{INT} \times 1 \text { Tahun) }\end{array}$ & 7.41 tahun/year \\
\hline
\end{tabular}

Keterangan/ Remaks:

TVCt $=$ Total Biaya Variabel Per Trip/ Total Cost Variable Per Trip (TVC/ Jumlah Trip Per Tahun/ TVC/Total of Trips Per Year $=$ Rp. $184.255 .042 / 26=$ Rp. 7.086.732,38)

$\mathrm{ICI}=$ Total Investasi Awal/Total of Initial Invesment (Rp. 264.600.000,-)

INT = Biaya Bunga Investasi Awal/Total Cost of Initial Investment $(0,135 \times \mathrm{ICl}=0,135 \times$ Rp. $264.600 .000,-=$ Rp. 35.721.000,-) 
dalam usaha penangkapan ikan menggunakan pukat cincin mini, dalam kajian ini digunakan rasio penerimaan-biaya untuk mengetahui besarnya nilai perbandingan antara penerimaan dan biaya produksi yang digunakan.

Berdasarkan hasil perhitungan pada Tabel 8, diketahui bahwa nilai rasio penerimaan-biaya usaha penangkapan pukat cincin mini sebesar 1,18 artinya rata-rata setiap nelayan pukat cincin mini melakukan operasi penangkapan ikan hanya memperoleh penerimaan sebesar 1,18 kali lipat atas biaya yang telah dikeluarkan atau dengan kata lain akan memperoleh penerimaan sebesar $118 \%$ dari biaya yang dikeluarkan atau menguntungkan (RC Ratio > $1)$.

\section{Analisis Rentabilitas}

Perhitungan rentabilitas merupakan perbandingan antara keuntungan (pendapatan bersih nelayan pemilik/juragan darat) selama periode tertentu dengan modal yang dipergunakan untuk menghasilkan keuntungan tersebut.

Perhitungan rentabilitas penting artinya dalam usaha penangkapan ikan, karena keuntungan yang besar belum merupakan ukuran bahwa usaha penangkapan tersebut telah bekerja dengan efisien. Salah satu ukuran efisiensi adalah melalui perhitungan rentabilitas, yaitu dengan cara membandingkan antara keuntungan yang diperoleh dengan modal investasi. Dari Tabel 9, diketahui bahwa rentabilitas untuk usaha penangkapan pukat cincin mini diperoleh nilai sebesar $19,32 \%$, yang berarti bahwa usaha tersebut berjalan kurang efisien karena memiliki tingkat kemampuan yang rendah dalam memperoleh keuntungan (nilai rentabilitas di bawah $25 \%$ )

\section{Analisis Periode Kembali Modal}

Perhitungan periode kembali modal diperlukan untuk mengetahui periode waktu pengembalian investasi sehingga dapat menggambarkan panjangnya

Tabel 9. Distribusi pendapatan pada usaha penangkapan ikan menggunakan pukat cincin mini selama satu tahun di Kabupaten Tuban, Jawa Timur, 2002

Tabel 9. Income distribution for fish capture with mini purse seine during one year in Tuban District, East Java, 2002

\begin{tabular}{|c|c|c|}
\hline Uraian/ltem & $\begin{array}{c}\text { Jumlah/ } \\
\text { Totals (Rp.) }\end{array}$ & $\begin{array}{c}\text { Persen/Percentage } \\
(\%)\end{array}$ \\
\hline 1. Penerimaan Total/Total Revenue & 351.727 .250 & 100.00 \\
\hline 2. Distribusi Pendapatan//ncome Distribution & & \\
\hline a. Nelayan Pemilik/Owner Fishermen & 52.501 .104 & 14.92 \\
\hline b. Nelayan Pandega/Labour Fishermen: & 64.001 .104 & 18.20 \\
\hline - Bagian Pandega/Labour Income Sharing & 52.501 .104 & 14.92 \\
\hline - Lawuan Pandega/Labour "Lamian" & 3.630 .080 & 1.03 \\
\hline - Uang Makan Pendega/Labour Meals & 6.869 .920 & 1.95 \\
\hline c. Bagian Current Input & 235.225 .042 & 66.88 \\
\hline - Total Biaya Tetap/Totals of Fixed Cost & 62.470 .000 & 17.76 \\
\hline $\begin{array}{l}\text { - Total Biaya Variabel Sebelum Operasi / } \\
\text { - Totals of Variable Cost Before Operation }\end{array}$ & 129.025 .000 & 36.68 \\
\hline $\begin{array}{l}\text { - Total Biaya Variabel Setelah Operasi *) / } \\
\text { Totals of Variable Cost After Operation }\end{array}$ & 20.230 .042 & 57.52 \\
\hline - Pengisi/Fillers & 3.116 .000 & 0.88 \\
\hline - Penguras/Drainers & 4.674.000 & 1.33 \\
\hline - Kuli Angkut/Longshoremens & 1.558 .000 & 0.44 \\
\hline - Izin Usaha/Licency & 150.000 & 0.04 \\
\hline - Retribusi/Retribution & 10.732.042 & 3.05 \\
\hline $\begin{array}{l}\text { - Total Biaya Pemeliharaan/ } \\
\text { Totals of Maintenance Cost }\end{array}$ & 23.500 .000 & 6.68 \\
\hline
\end{tabular}

") Total biaya tidak tetap (variabel) setelah operasi dikurangi biaya lain -lain /Total of variable cost after operation lessed others cost

(Rp. 31.730.042,-- Rp. 11.500.000,- = Rp. 20.230.042,-) 
waktu yang diperlukan agar dana yang ditanam pada suatu usaha dapat diperoleh kembali seluruhnya.

Pada usaha penangkapan ikan menggunakan pukat cincin mini, perhitungan periode kembali modal merupakan perbandingan antara modal investasi dengan keuntungan (pendapatan bersih nelayan pemilik/juragan darat) selama satu tahun. Hasil dari perhitungan tersebut kemudian dibandingkan dengan periode kembali modal maksimum, yaitu perbandingan antara modal investasi dengan bunga modal investasi dengan asumsi bahwa modal investasi tersebut didepositokan ke bank, dalam hal ini bank $\mathrm{BRI}$ dengan tingkat bunga pinjaman sebesar $13,5 \%$ per tahun

Dari Tabel 8, diketahui bahwa periode kembali modal usaha penangkapan ikan menggunakan pukat cincin mini mencapai 5,04 tahun, yang berarti bahwa seluruh modal investasi yang dikeluarkan untuk usaha ini akan kembali selama tempo waktu tersebut. Bila dibandingkan dengan periode kembali modal maksimum (7,41 tahun), ternyata usaha penangkapan ikan menggunakan pukat cincin mini di Kabupaten Tuban, Jawa Timur kurang efisien, karena memiliki waktu pengembalian yang mendekati sama.

\section{Distribusi Pendapatan}

Perhitungan distribusi pendapatan ditujukan untuk mengetahui berapa persen dari hasil tangkapan didistribusikan untuk kelompok-kelompok yang terlibat dalam usaha tersebut, seperti nelayan pemilik, nelayan pendega dan bagian hasil nelayan pemilik yang ditransfer ke luar sektor perikanan berupa pengeluaran investasi (current invesment).

Distribusi pendapatan tersebut dihitung dengan pendekatan akuntansi yaitu dengan membagi antara bagian hasil yang didistribusikan untuk setiap kelompok (nelayan pemilik, nelayan pandega dan current inputs) dengan nilai total hasil tangkapan. Bagian hasil yang diterima oleh nelayan pandega sesuai dengan sistem bagi hasil yang berlaku adalah $50 \%$ dari nilai bersih penjualan hasil tangkapan ditambah uang makan pandega ( $25 \%$ dari total hasil tangkapan dikurangi uang makan nelayan pemilik), "pacokan" (20 kg setiap ABK) dan "lawuhan" (2\% dari hasil tangkapan) sedangkan bagian hasil yang diterima nelayan pemiliki adalah $50 \%$ dari nilai bersih penjualan hasil tangkapan (Rp. 52.501.104,-). Dari Tabel 9, diketahui bahwa pendapatan yang didistribusikan untuk nelayan pandega sebesar $18,20 \%$ dan nelayan pemilik sebesar $14,92 \%$ dan "current input" sebesar $66,88 \%$.

Distribusi pendapatan nelayan pandega sebesar Rp. 64.001.104,- disebarkan kepada enam kelompok pandega. Dari Tabel 10, diketahui bahwa besarnya distribusi pendapatan yang diterimakan kepada nelayan pandega bervariasi, terbesar diperoleh nakhoda yaitu sebesar $2,95 \%$ dan terkecil diperoleh

Tabel 10. Distribusi pendapatan nelayan pandega pada usaha penangkapan ikan menggunakan pukat cincin mini selama satu tahun di Kabupaten Tuban, Jawa Timur, 2002

Tabel 10. Labour fishermen income distribution for fish capture with mini purse seine in Tuban District, East Java, 2002

\begin{tabular}{lccccc}
\hline $\begin{array}{l}\text { Distribusi Pendapatan/ } \\
\text { Income Distribution }\end{array}$ & $\begin{array}{c}\text { Individu } \\
\text { (Orang)/ } \\
\text { (Man) }\end{array}$ & $\begin{array}{c}\text { Distribusi Per } \\
\text { Kelompok/ } \\
\text { Distribution Per } \\
\text { Group (Rp.) }\end{array}$ & $\begin{array}{c}\text { Persen/ } \\
\text { Percen- } \\
\text { tage\% }\end{array}$ & $\begin{array}{c}\text { Distribusi Per } \\
\text { Orang/Distribution } \\
\text { Per Man (Rp.) }\end{array}$ & $\begin{array}{c}\text { Persen/ } \\
\text { Percen- } \\
\text { tage\% }\end{array}$ \\
\hline $\begin{array}{l}\text { Pendapatan } \\
\text { Pendega/Labour Income }\end{array}$ & & 64.001 .104 & 18.20 & & \\
$\begin{array}{l}\text { Distribusi/Distribution } \\
\text { a. Nakhoda/ Captain }\end{array}$ & 1 & 10.375 .954 & 2.95 & 10.375 .954 & 2.95 \\
$\begin{array}{l}\text { b. Juru Mesin/Engineer } \\
\text { c. Juru Lampu/Lighter }\end{array}$ & 1 & 7.280 .754 & 2.07 & 7.280 .754 & 2.07 \\
$\begin{array}{l}\text { d. Juru Arus/Currenter } \\
\text { e. Pandega Biasa/ }\end{array}$ & 1 & 6.577 .300 & 1.87 & 6.577 .300 & 1.87 \\
$\quad$ Labour fisherman & 13 & 5.416 .600 & 1.54 & 5.416 .600 & 1.54 \\
& & 34.633 .752 & 9.77 & 2.664 .135 & 0.75 \\
\hline
\end{tabular}


nelayan pandega biasa yaitu sebesar 0,75\%. Hal ini disebabkan oleh adanya perbedaan fungsi (tugas) antar nelayan pandega yang berpengaruh pula terhadap bagian hasil yang diperoleh.

\section{KESIMPULAN DAN SARAN}

\section{Kesimpulan}

Berdasarkan hasil analisis profitabilitas, usaha penangkapan ikan menggunakan alat tangkap pukat cincin mini di Kabupaten Tuban dinilai berada pada kondisi usaha yang menunjukkan gejala ke arah kurang menguntungkan dan tidak efisien. Hal ini ditunjukkan oleh: (a) nilai rasio penerimaan-biaya yang mendekati satu, yaitu 1,18, (b) nilai rentabilitas yang tergolong rendah, yaitu 19\% (di bawah 25\%), dan (c) periode kembali modal sebsar 5,04 tahun yang mendekati sama dengan periode kembali modal maksimum (7,41 tahun).

Pendapatan yang dihasilkan dari hasil usaha penangkapan ikan dengan alat tangkap pukat cincin mini di Kabupaten Tuban didistribusi ke dalam tiga kelompok besar yaitu sebesar 14,92\% untuk nelayan pemilik, 18,20\% untuk nelayan pandega dan 66,88\% untuk "current input".

\section{Saran}

Mengingat usaha penangkapan ikan dengan menggunakan alat tangkap pukat cincin mini di Kabupaten Tuban, Jawa Timur menunjukkan gejala rendahnya keuntungan dan efisiensi, perlu dilakukan upaya-upaya untuk meningkatkan tingkat keuntungan dan efisiensi serta memperhatikan optimalisasi ketersediaan sumberdaya ikan dengan tingkat penangkapan pada suatu wilayah penangkapan ikan yang dilakukan melalui riset yang lebih mendalam sehingga diperoleh alternatif kebijakan berupa terobosan program pemerintah yang mempunyai efektifitas tinggi. Dalam hal ini seperti kemungkinan untuk mendorong nelayan untuk melakukan penangkapan ikan pada perairan yang lebih jauh dengan sumberdaya ikan yang jauh lebih banyak.

\section{DAFTAR PUSTAKA}

Arifin, J. 2000. Manajemen Proyek Terapan. Elexmedia Komputindo. Jakarta. p. 264-265.

Barus H.R. dan Nasution, C. 1982. Purse Seiene Sebagai Alat Tangkap Lemuru (Sardinella longiceps) di Selat Bali. Balai Penelitian Perikanan Laut. Jakarta. Jurnal Penelitian Perikanan Laut. 4. p.15-19.

Direktorat Jenderal Perikanan Tangkap. 2001. Statistik Perikanan Tangkap Tahun 2001. Direktorat Jenderal Perikanan Tangkap. Departemen Kelautan dan Perikanan. Jakarta. $126 \mathrm{pp}$

Harahap N. 1993. Kekuatan Tradisi dalam Sistem Bagi Hasil dan Analisis Profitablitas Usaha Penangkapan Ikan di Jawa Timur. The Toyota Foundation. Tidak dipublikasi. $221 \mathrm{pp}$

Hernanto, F. 1998. Ilmu Usahatani. Penerbit Swadaya. Jakarta. p. 200-222

Nurhakim, S., JCB Uktolseja, Badrudin dan IGS Merta. 1998. Potensi, Penyebaran dan Pemanfaatan Sumberdaya Ikan di Indonesia. Balai Penelitian Perikanan laut. $29 \mathrm{pp}$

Purwanti P. 1994. Curahan Waktu dan Propduktivitas Kerja Nelayan di Kecamatan Pasuruan. Thesis UGM. Tidak diterbitkan. $173 \mathrm{pp}$

Riyanto B. 1995. Dasar-Dasar Pembelanjaan Perusahaan. Yayasan Badan Penerbit Gajah Mada. Yogyakarta. p. $35-51$

Sisdjatmiko. 1990. Kajian Dasar Pengantar Teori Ekonomi Mikro. Rineka Cipta. Jakarta. 61 pp.

Waluyo S. 1993. Penggunaan Lampu Sebagai Alat Bantu Penangkapan. Balai Penelitian Perikanan Laut. Jakarta. Jurnal Penelitian Perikanan Laut. 6. p. 24

Winarso B., Nurasa C. dan Nikijuluw V.P.H. 2001. Pemberdayaan perikanan berdasarkan analisis rentabilitas sumber daya perairan Laut Utara Jawa. dalam Prosiding: Perspektif Pembangunan Pertanian dan Kehutanan Tahun 2001 Ke Depan. Puslitbang Sosial Ekonomi, Balitbang Pertanian. Jakarta. p. 493-514. 